\title{
Rhetorical Moves in Problem Statement Section of Iranian EFL Postgraduate Students' Theses
}

\author{
Vahid Nimehchisalem (Corresponding author) \\ English Language Department, Faculty of Modern Languages \& Communication, Universiti Putra Malaysia, Malaysia \\ Email: vahid@upm.edu.my \\ Zahra Tarvirdizadeh \\ English Language Department, Faculty of Modern Languages \& Communication, Universiti Putra Malaysia, Malaysia \\ Sara Sayed Paidary \\ English Language Department, Faculty of Modern Languages \& Communication, Universiti Putra Malaysia, Malaysia \\ Nur Izyan Syamimi Binti Mat Hussin \\ English Language Department, Faculty of Modern Languages \& Communication, Universiti Putra Malaysia, Malaysia
}

Doi:10.7575/aiac.alls.v.7n.4p.173

URL: http://dx.doi.org/10.7575/aiac.alls.v.7n.4p.173
Received: 16/04/2016

Accepted: 19/06/2016

\begin{abstract}
The Problem Statement (PS) section of a thesis, usually a subsection of the first chapter, is supposed to justify the objectives of the study. Postgraduate students are often ignorant of the rhetorical moves that they are expected to make in their PS. This descriptive study aimed to explore the rhetorical moves of the PS in Iranian master's (MA) degree theses. The study focused on 30 PSs written by MA Teaching English as a Foreign Language (TEFL) students. The samples were analyzed based on Swales' (1990) Create-a-research-space (CARS) model. The findings revealed the students' flaws in writing the PS where they typically presented the significance of their study. The results of the analysis of their written samples also showed that some of the students failed to address a problem as an academic issue based on the existing gap in the previous studies and failed to recommend ways to solve the problem. Students' awareness of the rhetorical structure of the PS may help them create higher-quality works in academic settings. This study has theoretical and pedagogical implications, a discussion of which concludes the paper.
\end{abstract}

Keywords: Genre, Rhetorical structure, Problem Statement, Swales CARS model, MA theses, EFL learners

\section{Introduction}

Thesis writing is a challenging task for English as a Second Language (ESL) or English as a Foreign Language (EFL) learners (Zhu, 2001). Although a number of studies have been conducted throughout the world on EFL/ESL students whose mother tongues differ in their rhetorical structures from that of English, still "L2 postgraduate thesis remains something of a neglected genre" (Hyland, 2004, p. 134). Among various parts of proposals and theses, the Problem Statement (PS) section, despite its fundamental role in a study, has attracted less attention from scholars and educators (Jalilifar, Firuzmand \& Roshani, 2011; Ibrahim \& Nambiar, 2011). Previous studies (e.g. Jalilifar et al., 2011; Hernon \& Schwartz, 2007; Metoyer-ruraa \& Hemon, 1994; Stansbury, 2002) show that PS is the most important section in a thesis and proposal. Samraj (2008) pointed that MA and Ph.D students should be aware of this.

The PS section is a part of a research report that contains the topic of the study, the research problem within this topic, a justification for the problem based on past research and practice, deficiencies or shortcomings of past research or practical knowledge, and the importance of addressing it for diverse audiences (Creswell, 2012, p. 12). Metoyer-Duran and Hernon (1994) have defined the PS as "the crystallization of the issue, the essence of what I am doing" (p. 107). In a PS, an academic issue is introduced as a problem or claim which is then established and supported by evidence from the previous literature. In other words, the writer is required to introduce an academic issue as a problem and answer the question "What do I want to prove?" (Karbach, 2010, p. 89). Consequently, the PS is the most important section as the whole study must be conducted in its response (Hernon \& Schwartz, 2007; Stansbury, 2002). Everything that goes into a research has to do with the presentation, exploration and proof of the research problem (Nenty, 2009). According to Selamat (2008), "the heart of any research project is the problem" and "researchers get off a strong start when they begin with an unmistakably clear statement of the problem" (Nenty, 2009, p. 21).

The PS should be written in an understandable and clear way for various audiences. A satisfactory level of writing proficiency is required in different genres and academic settings. Williams (2005) argues that "lack of writing proficiency can be a barrier to academic and professional success" (p. 1). The writing proficiency means mastering to write different types of texts for different types of discourse communities. What is important to note at this point is that 
writing proficiency should not be limited to the writer's linguistic competence alone. Besides its linguistic accuracy, the rhetorical structure of a piece of writing should also be considered. What complicates this issue is that the rhetorical structure usually varies across languages and cultures (Kaplan, 1966). This means that a logical argument is culturebound. That is, what is regarded as a logical argument in one language may not be judged to be so in another. As a consequence, the differences between the rhetorical structure of English and other languages may create difficulties for EFL/ESL students in their writing even though they presumably have a high English proficiency level.

Study on rhetorical structure of various written parts of theses is significant for both ESL/EFL learners and lecturers (Harklau, 2002). Inasmuch as PS is an important sub-section of any research, having the ability to produce it with an appropriate rhetorical structure is a vital skill in writing research reports or proposals. According to Hernon and Schwartz (2007, p. 309), "research is like dealing with a set of propositions in a debate or an argument adhering to the principles of logic," and obtaining approval of the conclusion is the researcher's main aim. Among thesis prepositions, PS is the first and most important one that should be accepted before other prepositions, but there seems to be continuing confusion as to what comprises a sound PS (Hernon \& Schwartz, 2007). Having reviewed a number of studies conducted on the different parts of a thesis including abstract, introduction, literature review, finding, and discussion, one will find out few studies have focused on the PS, an area which needs to be investigated (Ibrahim $\&$ Nambiar, 2011; Peter, 2007).

\subsection{The CARS model (Swales, 1990)}

A theoretical framework is needed to define, organise, and classify the rhetorical structure of a text. A well-established model that has been used in many studies to identify and analyze the content and organisation of a written text, is Swales' (1990) Create-a-research-space (CARS) model. Based on the model, in order to write a well-organized piece, a writer is required to make a number of moves and take a number of steps (Figure 1).

\begin{tabular}{ll|}
\hline Move 1 & Establishing a territory: \\
\hline - & Step 1 Claiming centrality and/or \\
- & Step 2 Making topic generalization(s) and/or \\
- & Step 3 Reviewing items of previous research \\
\hline & Move 2 \\
\hline - & Step 1A Counter-claiming or \\
- & Step 1B Indicating a gap or \\
- & Step 1C Question-raising or \\
- & Step 1D Continuing a tradition \\
\hline & Move 3 \\
\hline - & Step 1A Outlining purposes or \\
- & Step 1B Announcing present research \\
- & Step 2 Announcing principal findings \\
- & Step 3 Indicating Research Article structure \\
\hline
\end{tabular}

Figure 1. The CARS model (Swales, 1990, p.141)

The model comprises three moves. These moves are rhetorical movements with specific communicative purposes or intentions. As the figure also illustrates, some steps are optional and it is not necessary for one move to follow all its steps (Swales, 1990). For example, the writer may only rely on S1A and S1B to present M2. The first Move (M1) involves establishing a territory and setting the domain of the study. Any claim that is made (Step 1) may be generalized (Step 2) and/or supported by providing relevant evidence (Step 3). More graphically, the breakdown of M1 could be illustrated as follows:

\footnotetext{
Text (PS) of Previous Research) = M1 (Establishing a Territory Intentions)
}

In M1, the research problem is presented (S1) and continued by generalizing the topic of the research (S2). Then, reviewing examples from the past research (S3) provides evidence to support the research problem. As the second Move (M2), a niche is established by taking any or all the four steps. In M2, counterargument(s) may be presented (S1A), gap(s) may be presented (by reference to the related previous studies), or questions may be addressed. The final Move (M3) is where the niche is occupied, which is accomplished by solving the problem. This move invloves indicating how the problem might be solved and who would benefit from the fulfilment of the research objective. In M3, S1 can be proposed in two forms; (A) by proposing the main purpose of the research or (B) by describing what would be considered as the main features of the study (Swales, 1990, p.159). According to Swales (1990), there are 
linguistic cues that can signal $\mathrm{M}$ and S. For example, words like 'although' and 'however' typically indicate M2S1 (Counter-claiming).

Following the CARS model, this study assumes that a PS should have three sections as illustrated in Table 1.

Table 1. Sections of PS based on the CARS model

\begin{tabular}{ll}
\hline CARS model (Swales, 1990) & $\begin{array}{l}\text { Sections of a PS } \\
\text { Move 1: Establishing a territory }\end{array}$ \\
$\begin{array}{l}\text { Section 1: Representation of academic issue as the } \\
\text { problem or claim }\end{array}$ \\
$\begin{array}{l}\text { Section 2: Indication the gap/deficiency } \\
\text { Move 3: Occupying the niche }\end{array}$ & \begin{tabular}{l} 
Section 3: Achievement the goal to be beneficial \\
\hline
\end{tabular}
\end{tabular}

As shown in the table, first an academic issue should be presented in the form of a problem or a claim. This corresponds with the first Move in the CARS model. Section 1 should be supported by evidence and in reference to previous literature. The gap should be indicated in Section 2 that corresponds with M2 in the CARS model. Lastly, Section 3 should focus on the achievement of the goal and how it will be beneficial based on the researcher's point of view. This corresponds with the representation of problem-solving in the CARS model.

\subsection{Previous Studies}

To date, numerous studies have been published which used the CARS model in their analyses. In most studies the model was used to define the organisation and sequences of moves in the introductions of Research Articles (RA). To offer an example, Samraj (2008) analyzed the introduction section of 24 theses selected randomly from the philosophy, biology, and linguistics disciplines in a large public university in the U.S. In addition to the analysis of the theses, semistructured interviews were also conducted with three professors from that university. It was reported that the introduction sections of biology and linguistics theses were similar in using rhetorical structure but varied in the last move. It was also found that the structure of introduction sections in the philosophy theses were relatively complicated (Samraj, 2008)

In a study in Malaysia, Ibrahim and Nambiar (2011) addressed the problem's implication in ESL postgraduate students' writing of a PS in their proposals or theses. They collected data through semi-structured questionnaires, interviews, and document analysis. The results showed that the students faced problems in reading and synthesizing previous studies. Further, the process of writing the PS turned out to be very complicated. They reported that their participants faced difficulty in identifying the important points and paraphrasing them. As they concluded, existence of rhetorical structure differences between participants' L1 and English language was the main culprit behind their writing difficulty; "English is linear while they were more familiar with a recursive style" (Ibrahim \& Nambiar, 2011, p. 1716).

In another study, Hirano (2009) also used the CARS model as an analytical tool. Hirano's exploratory study compared the rhetorical organization of research article introductions in Brazilian Portuguese and in English within a subfield of Applied Linguistics with a sample of 20 RAs. Based on the results, the Brazilian Portuguese, unlike English writers, used and followed different patterns from CARS model. The findings additionally indicated Swales' model as a useful analytical tool that could highlight differences related to rhetorical organization among various languages (Hirano, 2009).

Loi and Evans (2010) used Swales' model to analyse the rhetorical organization of the introduction sections of 20 English and 20 Chinese research articles. Their aim was analyzing the structures of moves and steps to find similarities and differences between these samples. They found that there were differences in using moves in Chinese rhetorical organization in writing introduction in comparison with those common in English. Loi and Evans (2010) attributed these differences to socio-cultural factors and rhetorical features in the Chinese language, which would require further investigations.

An exploratory study conducted by Yin Ling Cheung (2012) also used Swales' CARS model to examine the structure of an introductory chapter of a selected sample of master's theses in soft sciences disciplines in Singapore. For this purpose 43 theses were collected from a public university. The finding revealed a high frequency of using the integral citation in dissertations of applied linguistics and educational management students whereas showing low authorial presence and low frequency of using non-integral citation among instructional design and technology student writers (Cheung, 2012).

As shown above, the CARS model has been followed to focus on the introduction sections of theses rather than specifically focusing on the PS section. However, more search in the literature revealed that Jalilifar et al. (2011) analyzed the organisation of the PS sections of 100 master students' proposals and theses. The analysis was conducted within the single field of Applied Linguistics by using the CARS model. The finding of their study exposed with the exception of three steps, the others had been used obligatorily. Some sub-moves such as claiming centrality and outlining purposes were optional and thus observed in less than half of the proposals. The question raising (M2S1C) had low frequency. The researchers concluded that more studies were required to investigate the generic structure of proposals or theses (Jalilifar et al., 2011). 
To sum up, all the studies reviewed in this section regardless of pursuing rhetorical structure of the introduction section are common with the main objective of this study in using Swales' CARS model as a theoretical framework to identify the occurrences of the moves and their steps. Even though Swales' model has been often used to analyse the introduction section of proposals and theses, the model also seems suitable for analysing PSs. The lack of research in the rhetorical structure of the PSs as a crucial sub-section of the introduction section encouraged the researchers to conduct this study.

\subsection{Objective and Research Questions}

The study aims to identify MA Iranian EFL students' ability in composing a well-structured and well-organized problem statement that usually is a representation of an educational issue which needs a solution in their points of view. Therefore, the present study addressed the following questions:

1. What are the rhetorical structures of the PS sections of TEFL Iranian postgraduate students' theses based on the CARS model?

2. What linguistic features are employed in the PSs to indicate the rhetorical structures or Moves?

\section{Method}

A descriptive and qualitative approach with purposive sampling was employed to develop an in-depth exploration of Iranian writing ability in their theses. According to Creswell (2012), in qualitative research, participants and sites are selected purposefully to define the central phenomenon. The data consisted of 30 samples of PSs written by TEFL MA students $(60 \%$ males) from one public and one private university in Iran. The samples were collected from 18 MA graduates of Tarbiat Modares University (TMU) and 12 MA graduates of Islamic Azad University (IAU) in Tehran, Iran. All these graduates were currently working as lecturers in varying universities. The samples were purposively obtained with the writers' consent and permission from the English language department of both universities. The organization of the PSs were analysed based on Swales' (1990) CARS model (Figure 1). The analysis was done manually by the second and third authors as well as a third independent analyst, holding a PhD in Applied Linguistics. The moves and their sub moves or steps were defined, coded, and tabulated. Also, the linguistic features were highlighted as key codes used for realizing the moves and steps. The results from the three analysts were then crosschanged to ensure inter-rater reliability. Descriptive statistical methods including frequency and percentage were used to report the results.

\section{Results and Discussion}

The data were analyzed using Swales' CARS model. In this section, the results of analysis are presented in frequencies and percentages.

\subsection{Rhetorical Structure of the PS Samples}

To answer the first research question, the frequency and percentage of the moves and steps occurring in the samples

$(\mathrm{N}=30)$ were analyzed. Table 2 shows the results of this analysis.

Table 2. Frequency and percentage of occurrence of Moves in the samples $(\mathrm{N}=30)$

\begin{tabular}{lll}
\hline Move & Frequency & Percentage (\%) \\
\hline Move 1: Establishing a territory & 52 & 53 \\
Move 2: Establishing a niche & 25 & 25 \\
Move 3: Occupying the niche & 22 & 22 \\
\hline
\end{tabular}

As shown in the Table 2, M1 with 53\% had the highest percentage of occurrence in the samples while both M2 (25\%) and M3 (22\%) had relatively lower occurrence in the 30 samples. This finding shows that most of the writers were more concerned with establishing a territory (M1) rather than establishing (M2) or occupying a niche (M3). According to the results, M1 and its three steps were found almost in most of the samples. This means that the writers of the samples were aware that they were supposed to indicate and represent the territory of their studies as a crucial part of the PS section. In fact, the aim of this section would be to introduce the topic as an academic issue by referring to the literature to support it. M2 occurred in all the samples except for 5 (samples 9, 10,13, 15 and 17). This result shows somehow the writers' were not as aware of M2 as of M1, so a few failed to establish a niche as an important element in the PS sections. M3 had the lowest occurrences as compared with M1 and M2. The frequency and percentage of occurrence of the Steps are shown in Table 3. 


\begin{tabular}{lll}
\hline Table 3. Frequency and percentage of occurrence of Steps in the samples $(\mathrm{N}=30)$ & \\
\hline Step & Frequency & Percentage (\%) \\
\hline Move 1, Step 1: Claiming centrality & 19 & 37 \\
Move 1, Step 2: Making topic generalization & 7 & 13 \\
Move 1, Step 3: Reviewing items of previous research & 26 & 50 \\
\hline Move 2, Step 1A: Counter-claiming & 3 & 10 \\
Move 2, Step 1B: Indicating a gap & 15 & 48 \\
Move 2, Step 1C: Question-raising & 4 & 13 \\
Move 2, Step 1D: Continuing a tradition & 3 & 29 \\
\hline Move 3, Step 1A: Outlining purposes & 4 & 18 \\
Move 3, Step 1B: Announcing present research & 16 & 73 \\
Move 3, Step 2: Announcing principal findings & 2 & 9 \\
Move 3, Step 3: Indicating RA structure & 0 & 0
\end{tabular}

As per the Steps, M1S3 (Reviewing items of previous research) had the highest frequency and was observed in 26 samples. The second most frequent Step was M1S1 (Claiming centrality) which occurred in 19 samples, followed by M3S1B (Announcing present research) with a frequency of 16. A remarkable finding was that as one of the most important Steps in the PS section, M2S1B was missing in 15 samples, which means that half the students that wrote these samples failed to indicate the gap in the literature in the PS section of their theses. Based on the literature, this Step plays a vital role in justifying the research problem (Karbach, 2010; Lunsford, 2002). Jalilifar et al.'s (2011) results indicated a high percentage of $93 \%$ for this step that is considerably higher than the result of the current study. Steps $1 \mathrm{C}$ and 1D of the second Move also obtained lower percentages compared with the results reported by Jalilifar et al. (2011). The final Step of Move 3 (M3S3) never occurred in any of the samples, which may suggest it may not be required to the structure of the whole thesis in the PS section. A similar conclusion may also be made for the second Step of Move 3 (M3S2) which occurred only in two samples. This result may mean that the writer is not really required to indicate the principal findings in the PS section of a thesis or at least should not be penalized for not having done so.

As can be seen from the results, M1 and all its three Steps were presented in most of the samples. These results are similar to the same obtained by Jalilifar et al. (2011). The S1 (Making Topic Generalization) from M1 was seen 7 times $(13 \%)$ among the 30 samples and less than one-quarter of the total data. Finally, the S3 (Reviewing items of previous research) of M1 got 50\%. It can be concluded from this result that using the M1 and its steps were obligatory across various samples of PSs. This indicates the importance of the first Move and its Steps.

\subsection{Linguistic features employed in the PSS}

The second research question dealt with the linguistic features that signaled the different Moves made in the samples. The samples were analyzed to extract these linguistic features. This section presents a number of examples from varying samples for each Step of all three Moves.

Tables 4 to 6 summarize the results of analyzing the linguistics features used by the writers to signal the steps of the three Moves. Some of the linguistic features showing M1 and its 3 steps have been presented in Table 4.

Table 4. Examples of linguistic features signaling Move 1 Steps

\begin{tabular}{|c|c|}
\hline Step & Example (Sample number) \\
\hline $\begin{array}{l}\text { S1: } \\
\text { centrality }\end{array}$ & $\begin{array}{l}\text { It seems necessary to carry out some studies investigating differences.... (PS1) } \\
\text { After decades of efforts in designing and redesigning an efficient EFL...(PS2) } \\
\text { A substantial number of studies have investigated markers in general and specific markers in } \\
\text { particular...(PS3) }\end{array}$ \\
\hline $\begin{array}{l}\text { S2: Making topic } \\
\text { generalization }\end{array}$ & $\begin{array}{l}\text { Accordingly, practitioners so often mention hedging/boosting as the main problem...(PS6) } \\
\text { Among scholars who agree upon the importance of good vocabulary in a piece of } \\
\text { writing...(PS22) }\end{array}$ \\
\hline $\begin{array}{l}\text { S3: Reviewing } \\
\text { items of } \\
\text { previous } \\
\text { research }\end{array}$ & 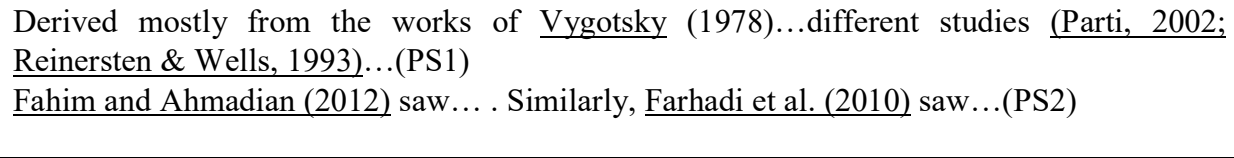 \\
\hline
\end{tabular}

Based on Table 4, it can be seen that the linguistic features employed in the samples to signal M1S1 (Claiming centrality) are words like 'necessary', 'decades of efforts', 'attracted increasing interest' which emphasize the need of doing or starting something. For M1S2 (Making topic generalization), words like 'so often', 'main problem' and 'agree upon' were used. As the examples for M1S3 (Reviewing items of previous research) indicate, the writers usually referred to previous works to support the claim or problem. Therefore, the names of the authors of previous studies 
function as the signals for this Step. The linguistic features signaling the four Steps of the second Move are presented in Table 5 .

Table 5. Examples of linguistic features signaling Move 2 Steps

\begin{tabular}{|c|c|}
\hline Step & Example (Sample number) \\
\hline $\begin{array}{l}\text { S1A: } \\
\text { claiming }\end{array}$ & $\begin{array}{l}\text { Unfortunately, the notion of gambits, subsumed under communication has been } \\
\text { misunderstood... (PS4) } \\
\text { Nonetheless, there are a few flaws that cast a shadow on its merits...(PS20) }\end{array}$ \\
\hline $\begin{array}{l}\text { S1B: Indicating a } \\
\text { gap }\end{array}$ & $\begin{array}{l}\text {...there is a gap }- \text { having no idea about the best way of ... a need of conducting research to } \\
\text { fill this gap...(PS1) } \\
\text { Most of the previous researchers... have not paid due attention to boosting...(PS6) }\end{array}$ \\
\hline $\begin{array}{l}\text { S1C: } \\
\text { question }\end{array}$ & $\begin{array}{l}\text { Now the question is to what extent these new developed EL textbooks invoke critical } \\
\text { thinking skills...(PS2) } \\
\text {... } \underline{\text { but in case of written performance, the results remain unclear...(PS11) }}\end{array}$ \\
\hline $\begin{array}{l}\text { S1D: Continuing a } \\
\text { tradition }\end{array}$ & $\begin{array}{l}\text { As one of the main language skills is reading, it's important to pave the path of its } \\
\text { understanding. (PS19) } \\
\text { Therefore, in this investigation the performance of the learners on a listening comprehension } \\
\text { test... will be compared with that ...(PS28) }\end{array}$ \\
\hline
\end{tabular}

Based on Table 5, the first Step (S1A: Counter-claiming) of Move 2 (M2: Establishing a niche) was signaled by linguistic features such as 'has been misunderstood', 'nonetheless', and 'flaws' as this Step is mostly used to create an argumentative tone. Counter-claims show the reader that the writer is capable of anticipating and responding to the opposing parties which indicates the writer's critical thinking skills and motivates readers to continue reading. The linguistic features for the second Step (S1B: Indicating a gap) were lexical items such as 'a gap', 'fill this gap' and 'have not paid due attention'. Such expressions are often used for indicating that the writer is well aware of the gap in the literature. The next Step (S1C: Raising a question) was signaled by expression like, 'question is to what extent' 'but', and 'remain unclear'. Lastly, the final Step (S1D: Continuing a tradition) was signaled by expression such as 'it's important', 'therefore' and 'compared'. The results of the final Move (M3: Occupying the niche) have been presented in Table 6.

Table 6. Examples of linguistic features signaling Move 3 Steps

\begin{tabular}{|c|c|}
\hline Step & Example (Sample number) \\
\hline \multirow{3}{*}{$\begin{array}{l}\text { S1A: } \\
\text { purposes }\end{array}$} & So it will be the goal of the present study to investigate and compare... (PS1) \\
\hline & The purpose of this study is to evaluate.../ Here, the purpose is not to criticize (PS16) \\
\hline & The purpose was to see which one brings better results...(PS24) \\
\hline \multirow{2}{*}{$\begin{array}{l}\text { S1B: Announcing } \\
\text { present } \\
\text { research }\end{array}$} & ...the present study attempted to: (a) develop a typology of the Rhetorical Markers...(PS3) \\
\hline & This is particularly what this study sets out to find. (PS4) \\
\hline \multirow{2}{*}{$\begin{array}{l}\text { S2: Announcing } \\
\text { principal } \\
\text { findings }\end{array}$} & $\begin{array}{l}\text { The research supports the contention that stress affects teachers' effectiveness with students } \\
\text { (Blasé 1982). (PS10) }\end{array}$ \\
\hline & The result is expected to provide reading insight into...(PS18) \\
\hline
\end{tabular}

The first Step of this Move (S1A: Outlining purposes) is signaled by the words 'goal' and 'purpose' which are typically used to indicate the main objective of a study. The second Step (S1B: Announcing present research) is indicated by lexical items such as 'attempted' and 'sets out'. Both steps are the indication of the goals and purposes of a study. They are optional and their use depends on the writer's viewpoint. According to the available literature on research methods, it is recommendable to state who would benefit from problem solving at the end of a PS section. The lack of this step could be supposed as the students' flaw in presenting a well-structured PS. The final Step (S2: Announcing main findings) was found only in two samples (PS10 and PS18) with linguistic features such as 'research supports' and 'result is expected'. Finally, the last Step (S3: Indicating Research Article structure) of M3 was not found in any of the samples. 


\section{Conclusion}

As mentioned before, PS has a major function in proposals and theses, but little attention has been paid to its rhetorical structure (Moves and Steps). Identifying the Moves and their Steps in PSs based on Swales' model and identifying the linguistic features required to distinguish them were the main objectives of this study. PS is supposed to play the role of an introducer in a thesis. In the PS section of a thesis, an academic or research issue is presented and the justifications for conducting a study are set forth. In this study, the PSs of 30 sample theses by EFL Iranian MA graduates were analysed rhetorically and structurally. The CARS model of moves is often used to analyze the introduction section of proposals or theses, however, the novelty of the current study is using this model to analyse only the PS section which is supposed typically a separate kind of introduction for presenting the central issue, objectives, and the questions of the study.

The results revealed that M1and its three steps have been found in all samples. M2 and its all steps have occurred in all samples except for 5 samples (PS9, PS10, PS13, PS15 and PS17). Step1A and S2 of M3 occurred in some samples and S1B occurred in most samples. Finding of M3 is contrary to what has been reported by Jalilifar et al. They mentioned that Iranian MA students do not tend to reveal the purpose of their studies in this section. While the results of this study reveal that M3S1b has occurred in $73 \%$ of the total samples.

Based on the results, in the majority of the samples the Moves and their Steps were missing. This negatively affects the rhetorical structure of the PS which can be attributed to the writer's lack of knowledge about the adequate structure of the PS. It can be concluded that these graduates require some sort of training on the rhetorical structure of the problem statement section. The fact that they are all lecturers at the moment further underscores the necessity of such training.

The results clearly showed that most of the samples lacked most of the necessary Moves and Steps for a PS. Therefore, it is recommended that candidates in post-graduate levels be made aware of the important roles of the PS in a thesis. A PS should provide structural strength to the presentation of argument, method, and analysis, on one hand (Stansbury, 2002) while on the other hand, it should provide support for the target research objectives based on the previous literature (Hernon \& Schwartz, 2007).

The findings of this study could be helpful for both post-graduate candidates and their supervisors. They could help Iranian EFL students become aware of their own weaknesses while helping their supervisors support them in coping with their difficulties (Khodabandeh, 2014). In this regard, Metoyer-Duran and Hernon (1994) pointed out nine attributes for a well-structured PS, including:

1. clarity and precision (a well-written statement does not make sweeping generalizations and irresponsible statements);

2. identification of what would be studied, while avoiding the use of value-laden words and terms;

3. identification of an overarching question and key factors or variables;

4. identification of key concepts and terms;

5. articulation of the study's boundaries or parameters;

6. some generalizability;

7. conveyance of the study's importance, benefits, and justification (regardless of the type of research, it is important to address the "so what" question and to demonstrate that the research is not trivial);

8. no use of unnecessary jargon; and

9. conveyance of more than the mere gathering of descriptive data providing a snapshot.

The study contributes to theory in the area. Its results provide empirical proof for the fact that CARS model can be successfully used for analyzing PS section. It should however be noted that M3S2 occurred only in two samples while M3S3 was not found in any of the PS samples. This may be an indication of the fact that Swales' model may only be suitable for analyzing the PSs after slight modifications; however, such a claim needs to be verified by further research by analyzing similar samples written by professional and more mature authors. Despite these findings, the Swales' CARS model can raise postgraduate students' awareness on the important elements of a PS. The model and the samples analyzed in this study and similar studies can serve as helpful guidelines for students to produce well-structured PSs. Therefore this study has important implications for future practice. Providing better academic support and supervision are important to improve the quality of postgraduate theses.

Further studies regarding the role of PS in theses would be worthwhile to confirm the present results. It would be interesting to compare experiences of individuals within the same discipline by adding interview as the second instrument for collecting more in-depth data and explore the reasons behind students' flaws. Comparing PSs written by Iranian postgraduate students and native postgraduate students and comparing different theoretical frameworks to find out which would result in more accurate data would be some of the research recommendations for further study.

\section{References}

Cheung, Y. L. (2012). Understanding the Writing of Thesis Introductions: An Exploratory Study. Procedia - Social and Behavioral Sciences, 46, 744-749. doi:10.1016/j.sbspro.2012.05.191 
Connor, U. M. (1996). Contrastive Rhetoric: Cross-Cultural Aspects of Second Language Writing. New York: Cambridge Applied Linguistics.

Creswell, J. (2012). Educational research: Planning, conducting, and evaluating qualitative research (4th ed.). Pearson.

Harklau, L. (2002). The Role of Writing in Classroom Second Language Acquisition. Journal of Second Language Writing, 11, 329-350.

Hernon \&Metoyer-Duran, C. (1993). Problem Statements: An Exploratory of Their Function, Significance and Form. Library \& Information ScienceResearch, 15, 71-92

Hernon, P., \& Schwartz, C. (2007). What is a problem statement? Library and Information Science Research, 29(3), 307-309. doi:10.1016/j.lisr.2007.06.001

Hirano, E. (2009). Research article introductions in English for specific purposes: A comparison between Brazilian Portuguese and English. English for Specific Purposes, 240-250.

Hyland, K. (2004). Disciplinary interactions: Metadiscourse in L2 postgraduate writing. Journal of Second Language Writing, 13(2), 133-151. doi:10.1016/j.jslw.2004.02.001

Ibrahim, N., \& Nambiar, R. M. (2011). What is the problem with the statement of problem? : the case of postgraduate international students and the introductory sections of a project paper. Procedia Social and Behavioral Sciences, 17131717.

Jalilifar, A., Firuzmand, S., \& Roshani, S. (2011). Genre analysis of problem statement sections of MA proposals and theses in Applied Linguistics. Language, Society and Culture, (33), 85-93. Retrieved from http://scholar.google.com/scholar?hl=en\&btnG=Search\&q=intitle:Genre+Analysis + of + Problem + Statement + Sections $+\mathrm{o}$ $\mathrm{f}+\mathrm{MA}+$ Proposals+and+Theses+in+Applied+Linguistics\#1

Kaplan, R. B. 1966. Cultural Thought Patterns in Intercultural Education. Language Learning. 16, 1-20. doi:10.1111/j.1467-1770.1966.tb00804.x

Karbach, J. (1987). Using Toulmin's model of argumentation. Journal of Teaching Writing, 6(1), 81-91.

Khodabandeh, F. (2014). Argumentation across L1 and L2: Examination of Three Instructional Treatments of Genrebased Approach to Teaching Instructional Treatments of Genre-based Approach to Teaching. Elsevier, 968 975.doi:10.1080/17437270802417176

Lilian, B. L. (2004). Toulmin's Model of Argument and the Question of Relativism. In L. Bermejo-Luque, Rhetorical criteria for argument evaluation? (pp. 169-181). Murcia: University of Murcia.

Loi , C. K., \& Evans , M. S. (2010)). Cultural differences in the organization of research article introductions from the field of educational psychology: English and Chinese. Journal of Pragmatics, 2814-2825.

Lunsford, K. J. (2002). Contextualizing Toulmin's Model in the Writing Classroom: A Case Study. Written Communication.

Metoyer-Duran, C., \& Hernon, P. (1994). Problem Statements in Research Proposals And Published Research: A Case Study of Researchers' Viewpoints. Library \& Information Science Research, 16(2), 105-118. doi:10.1016/07408188(94)90003-5

Nenty, H. J. (2009). Writing a Quantitative Research Thesis. International J. Educ. Sci.1 (1):19-32. Retrieved onlineat:http://www.krepublishers.com/02-Journals/IJES/IJES-01-0-000-09-Web/IJES-01-1-000-09-Abst-P[Accessed on 20/10/11].

Stansbury, M. C. (2002). Problem statements in seven LIS journals: An application of the Hernon/Metoyer-Duran attributes. Library and Information Science Research, 24(2), 157-168. doi:10.1016/S0740-8188(02)00110-X

Samraj, B. (2008). A Discourse Analysis of Master's Theses across Disciplines with a Focus on Introductions. Journal of English for Academic Purposes, 55-67

Swales, M. J. (1990). Genre Analysis: Enlish in academic and research settings.Cambridge: Cambridge University Press.

Toulmin, S. E. (2003). The Uses of Argument (Updated edition 2003). Cambridge, Cambridge University Press. doi: $10.2307 / 2183556$

Williams, J. ( 2005). Teaching Writing In Second And Foreign Language Classrooms. McGraw-Hill.

Zhu, W. (2001). Performing Argumentative Writing in English: Difficulties, process, and strategies. TESL Canada Journal, 34-50. 